\title{
A SURVEY ON ITALIAN MEDICALS DURING COVID-19 OUTBREAK. COULD BACILLUS CALMETTE-GUÉRIN VACCINE BE EFFECTIVE AGAINST SARS-COV2?
}

\author{
Vincenzo Patella ${ }^{1}$, Alessandro Sanduzzi ${ }^{2}$, Dario Bruzzese ${ }^{3}$, Giovanni florio ${ }^{1}$, Raffaele \\ Brancaccio $^{1}$, Gabriella Fabbrocini ${ }^{4}$, and Gabriele Delfino ${ }^{1}$ \\ ${ }^{1}$ Presidio Ospedaliero Santa Maria della Speranza di Battipaglia \\ ${ }^{2}$ Department of Clinical Medicine and Surgery, Section of Respiratory Disease, University \\ of Naples Federico II \\ ${ }^{3}$ University of Naples Federico II Department of Public Health \\ ${ }^{4}$ Department of Clinical Medicine and Surgery, Dermatology, Section of Dermatology, \\ University of Naples Federico II
}

June 23, 2020

\begin{abstract}
Background: Epidemiological studies show that BCG vaccinated population seems to be more likely protected from COVID-19 infection, but WHO gave a stark warning on use of BCG vaccine without confirmed COVID-19 trials. The aim of this survey is to assess the ability and readiness to respond to viral infection by physicians who had been BCG vaccinated. Methods: After Ethical Committee authorization, professional orders were used to contact physicians with an online survey. Specialty, COVID-19 infection, and previous BCG vaccination were recorded. Statistical data analysis was performed. Results: 1906 medicals answered the questionnaire, $(\mathrm{M}=1068 ; \mathrm{F}=838 ;$ mean age $50.7+/-13.3 ;>24<87 \mathrm{yrs})$, more than half $(1062 ; 55.72$ \%) experienced BCG vaccination. Professional activity was recorded, and only 49 subjects (2.57\%) of them was infected by SARS-CoV2. Among the group of infected people, asymptomatic form occurred in 12 subjects (24.5\%); a pauci-symptomatic form in 24 subjects (49.0\%); a severe form (pneumonia and/or respiratory distress) in 13 (26.5\%). SARS-CoV2 infection rate was $2.17 \%(23 / 1062)$ in vaccinated group and $1.66 \%(14 / 844)$ in unvaccinated group $(\mathrm{p}=0.359)$. Conclusion: Our experience does not confirm the possible protective role of BCG against COVID-19, pending ongoing controlled trials. Although recent epidemiological studies point out in BCG vaccinated population a lower prevalence of SARS-CoV2 infection, in our cohort of physicians no significant difference was found in terms of prevalence of COVID-19 infection. Our data underline the necessity to follow the WHO warning about indiscriminate use of BCG vaccine, until clear evidence of protection by BCG vaccination against COVID-19 is fully demonstrated.
\end{abstract}

\section{Hosted file}

Paper_Could tuberculosis.docx available at https://authorea.com/users/336069/articles/461973a-survey-on-italian-medicals-during-covid-19-outbreak-could-bacillus-calmette-gu\%c3\%

A9rin-vaccine-be-effective-against-sars-cov2 